\title{
Preconceito de Gênero no Ambiente Escolar: A Formação Docente e a Disciplina de Gegrafia Como Promotoras de Uma Educação Cidadã
}

\section{Gender Bias in the School Environment: The Teacher Training and the Discipline of Geography as Promoters of a Citizen Education}

Jacqueline Praxedes Almeida*

Denis Rocha Calazans **

Jaqueline Silva Bomfim***

Jeremias Ferreira Oliveira***

\begin{abstract}
Resumo:
O Brasil ocupa o $7^{\circ}$ lugar no mundo em casos de feminicídios e o estado de Alagoas ocupa o $3^{\circ}$ lugar no ranking nacional. Nessa perspectiva, evidencia-se a importância de uma formação docente, para a promoção de uma educação voltada para o respeito às diferenças, na qual as questões sobre gênero estejam presentes. Este estudo, de natureza qualitativa e que optou pelo questionário como instrumento de recolha de dados, objetiva refletir sobre a importância da inclusão do tema gênero na formação do professor de Geografia e conhecer as percepções dos alunos de uma escola pública de Maceió/AL diante de uma situação real de exposição da mulher. A investigação revelou que muitos discentes banalizam ações machistas e desvalorizam a mulher.
\end{abstract}

\section{Abstract:}

Brazil ranks 7th in the world in cases of feminicide and the state of Alagoas occupies 3rd place in the country. In this perspective, it is clear the importance of teacher training, to the promotion of an education focused on the respect of differences, in which gender issues are present. This study, qualitative in nature and that the questionnaire was the choosen instrument of data collection, aims to reflect on the importance of including the gender theme in shaping the geography teacher and meet students 'perceptions of a public school in Maceió/ AL face a real situation of exposure. The investigation revealed that many students trivialize sexist behaviour and devalue women.

\begin{abstract}
* Prof ${ }^{a} \operatorname{Dr}^{a}$ do Curso de Geografia do Instituto de Geografia, Desenvolvimento e Meio Ambiente (IGDEMA) da UFAL

** Prof. MSc. do Instituto Federal de Alagoas

*** Graduanda(o) em Geografia da UFAL
\end{abstract}

Palavras-chave:

Preconceito de gênero, Formação docente, Educação e cidadania, Geografia escolar.

Key-Words:

Gender prejudice, Teacher training, Education and citizenship, School geography. 


\section{INTRODUÇÃO}

$\mathrm{O}^{\mathrm{p}}$ papel exercido pela mulher ao longo da história foi fruto das mais diversas formas de desigualdade existentes entre estas e os homens. Esse processo ocorre nas mais diversas sociedades ao longo da história. Segundo Pinsky (2014, p. 17),

Durante o longo período histórico em que as mulheres ficaram confinadas ao lar, suas vozes nunca foram ouvidas, seus problemas específicos não foram solucionados, suas reivindicações não foram atendidas, seus direitos não foram respeitados. Como elas estavam em casa, o poder era exclusivo dos homens, elas não tinham influência alguma nas decisões. As consequências disso foram péssimas para as mulheres: perderam a cidadania, o respeito, a dignidade.

A compreensão de que o papel desempenhado pela mulher, ao longo do tempo, é uma consequência das desigualdades impostas socialmente, vem fomentando no meio acadêmico a discussão sobre o preconceito de gênero. Essas discussões, no meio acadêmico e fora dele, motivaram vários movimentos em prol da igualdade entre homens e mulheres, seja na esfera pública ou privada. Para se falar em preconceito de gênero, deve-se primeiro entender o conceito de gênero. Segundo Souza e Ratts (2008, p. 150), "O uso da categoria gênero serviu para diferenciar-se da categoria sexo, pois as diferenças entre homens e mulheres corresponderiam a uma construção social e não a uma especificidade sexual biológica". Assim,

Para as ciências sociais e humanas, o conceito de gênero se refere à construção social do sexo anatômico. Ele foi criado para distinguir a dimensão biológica da dimensão social, baseando-se no raciocínio de que há machos e fêmeas na espécie humana, no entanto, a maneira de ser homem e de ser mulher é realizada pela cultura. Assim, gênero significa que homens e mulheres são produtos da realidade social e não decorrência da anatomia de seus corpos (BRASIL, 2009, p. 39 grifo do autor).

De acordo com esse conceito, a sociedade, ao longo da história, constrói maneiras diferentes de ser homem ou mulher, ou seja, como pessoas do sexo masculino ou feminino devem se vestir, se comportar socialmente, de quais tipos de brincadeira devem participar, quais profissões devem exercer, dentre outras.

A concepção binária de gênero, feminino e masculino, é criticada por Butler (2003), quando reflete sobre identidades que a matriz cultural não aceita ou permite existir. É o caso dos intersexuais, transexuais etc. e das situações em que o gênero não decorre do sexo, além daquelas em que o desejo não decorre nem do sexo nem do gênero. Esses aspectos levantados pela autora mostram algumas limitações dessa classificação na tentativa de explicar a diversidade humana, não sendo, no entanto, objeto deste trabalho aprofundar esse campo conceitual.

Em decorrência de a mulher ser o sexo a que está atribuído biologicamente a função de exercer a maternidade, "às mulheres, sempre foi reservado um lugar de menor destaque, seus direitos e seus deveres estavam sempre voltados para a criação dos filhos e os cuidados do lar, portanto, para a vida privada [...]" (SILVA, 2010, p. 557).

O preconceito de gênero é muitas vezes construído de forma despercebida, começando no ambiente familiar. No passado, por exemplo, a preferência por um filho homem já determinava elementos e padrões comportamentais de diferenciação. $\mathrm{Na}$ atualidade, no momento em que "mãe, pai e familiares recebem o resultado do ultrassom, passa-se a 'desenhar' o lugar da criança. Se menina, roupas e decorações cor-de-rosa. Se menino, tudo azul”' (BRASIL, 2009, p. 48).

Cria-se, dessa forma, uma dualidade que estabelece papéis pré-determinados para cada gênero dentro da estrutura social. Qualquer comportamento que não se enquadre nessas determinações é repreendido socialmente, muitas vezes sem nenhuma análise ou reflexão. Isso é o que chamamos de visão preconceituosa.

No que se refere à formação da sociedade brasileira, a figura feminina era vista como sendo inferior à do homem. Durante o período colonial, a exigência de submissão, recato e docilidade foi imposta às mulheres. Os poderes absolutos eram destinados ao homem, chefe e senhor da familia na sociedade patriarcal brasileira, enquanto às mulheres era destinada a obrigatoriedade da reclusão ao lar, com sua vida doméstica junto à criadagem escrava. Nesse período, as jovens que saíssem das "rédeas" das decisões de seus pais tinham como destino a internação em um convento ou a morte, alternativa mais drástica e plenamente aceitável socialmente, cabendo ao pai ou aos irmãos da moça sentenciarem e a executarem (ALMEIDA, 2014). Segundo Arbex (2013), até meados da segunda metade do século XX, as mulheres que não apresentavam um comportamento social aceitável ou que já não agradavam mais a seus maridos passaram também a ser internadas em hospitais psiquiátricos. Assim, era comum encontrar nos chamados hospícios

[...] filhas de fazendeiros as quais haviam perdido a virgindade ou adotavam comportamento considerado inadequado para um Brasil à época, dominado por coronéis e latifundiários. Esposas trocadas por amantes acabavam silenciadas pela internação [...]. Havia também prostitutas [...] [que] após cortarem com gilete os homens com quem haviam se deitado, mas que se recusavam a pagar pelo programa, [acabavam sentenciadas a internação em um manicômio] (ARBEX, 2013, p. 30).

$\mathrm{Na}$ atualidade, a situação da mulher no Brasil ainda é bastante crítica. Segundo dados do IPEA de 2011, o Brasil 
ocupa o $7^{\circ}$ lugar no mundo em casos de feminicídios, estando Alagoas no $3^{\circ}$ lugar no ranking nacional (IPEA, 2013).

Segundo pesquisa desenvolvida pelo IPEA (2014), os entrevistados concordaram, total ou parcialmente, com as seguintes afirmativas: "se as mulheres soubessem se comportar, haveria menos estupros" (58\%), "os homens devem ser a cabeça do lar" (64\%), "toda mulher sonha em se casar"' $(79 \%)$ e "casos de violência dentro de casa devem ser discutidos somente entre os membros da familia" (63\%). Os resultados obtidos pela pesquisa também demonstram que

O modelo patriarcal de família, além de pressupor a supremacia masculina, centra-se num arranjo familiar composto por homem, mulher e seus filhos. O modelo é androcêntrico e heteronormativo: coloca o homem e o masculino como referência em todos os espaços sociais. O universal, o neutro é masculino; é o homem que deve deter o poder - de decisão, de mando, de recursos e sobre o corpo e a mente da mulher (IPEA, 2014, p. 7).

Diante dessa realidade, a escola e os professores possuem papel fundamental na promoção de uma educação que repudia a violência e respeita a diversidade. Está entre as responsabilidades do professor, além de ensinar os conhecimentos acadêmicos, o desenvolvimento de valores para constituição de uma sociedade mais humana. Para tanto, se faz necessário que haja uma formação docente voltada para o abandono dos preconceitos e estereótipos.

A escola também tem, entre suas funções, o papel fundamental de combater a reprodução do preconceito de gênero, tendo em vista que

Quando a menina e o menino entram para a escola, já foram ensinados pela família e por outros grupos da sociedade quais são os "brinquedos de menino" e quais são os "brinquedos de menina". Embora não seja possível intervir de forma imediata nessas aprendizagens no contexto familiar e na comunidade, a escola necessita ter consciência de que sua atuação não é neutra (BRASIL, 2009, p. 50).

Por isso, deve-se estar atento às manifestações de gênero que ocorrem no ambiente escolar, cabendo ao professor tratar dessas questões em sala de aula, mas para isso é necessário que o profissional da educação tenha uma formação voltada para tal fim, já que este também

(...)tem a possibilidade de reforçar preconceitos e estereótipos de gênero, caso tenham uma atuação pouco reflexiva sobre as classificações morais existentes entre atributos masculinos e femininos e se não estiverem atentos aos estereótipos e aos preconceitos de gênero presentes no ambiente escolar (BRASIL, 2009, p. 51)

Diversos fatores podem reforçar o preconceito; ocorre, por exemplo, através da cultura, embutidos no poder midiático e religioso, através de seus valores e costumes disseminados na sociedade. A base da reprodução desse tipo de preconceito ocorre, principalmente, nos primeiros grupos sociais de convivência das crianças, "portanto família e escola são as principais responsáveis pelas masculinidades e feminilidades que estão sendo formadas em nossa sociedade" (CASAGRANDE, CARVALHO, SILVA, 2009, p. 2555).

Desconstruir a reprodução desse tipo de preconceito requer um olhar crítico e uma grande responsabilidade social, envolvendo todos os segmentos da sociedade. Nesse contexto, é necessário combater suas formas de reprodução através de uma educação cidadã para a igualdade de gênero. Nesse aspecto, a escola assume papel fundamental, devido à sua importância no processo formativo.

Partindo dessas concepções, o presente trabalho objetiva refletir sobre a importância da inclusão do tema gênero na formação do professor de Geografia como forma de favorecer ao licenciando o desenvolvimento de uma práxis educativa que contribua com a formação cidadã de seus futuros alunos, bem como apresentar os resultados da pesquisa desenvolvida pelos discentes do curso de Geografia Licenciatura da Universidade Federal de Alagoas (UFAL) na disciplina de Estágio Supervisionado II na escola campo de estágio, como forma de subsidiar o trabalho desses futuros professores, possibilitando-lhes, durante sua atuação profissional, a inserção do trabalho com questões ligadas a gênero na escola e nas aulas de Geografia.

\section{O PRECONCEITO DE GÊNERO NO AM- BIENTE ESCOLAR: O PAPEL DO PROFES- SOR NO COMBATE À DISCRIMINAÇÃO}

Para que a escola consiga cumprir o seu papel de combate ao preconceito, se faz necessário que os cursos de licenciatura preparem os futuros profissionais da educação para serem promotores de uma educação voltada para o respeito às diferenças e para a igualdade de gênero. Segundo Costa (2011), a formação do professor de Geografia e o seu comprometimento com o tema gênero em Geografia deveriam ser possibilitados nos cursos de graduação. No entanto, nas matrizes curriculares das universidades brasileiras, poucas, como o curso de Geografia Licenciatura, ofertado pela Universidade Estadual de Ponta Grossa (UEPG) e a Universidade Federal de Santa Maria (UFSM), possuem disciplina que aborda essa temática.

Nesse sentido, faz-se necessário analisar o que dizem os documentos oficiais a respeito da formação do professor e suas competências, pois são esses profissionais que estão sendo educados nas Instituições de Ensino Superior (IES) e que estarão nas salas de aula da Educação Básica, tendo entre suas responsabilidades a de contribuir na formação cidadã de 
seus futuros alunos.

De acordo com a Lei de Diretrizes e Bases da Educação Nacional (LDB), no Art.43, primeiro parágrafo, a educação superior tem como uma das finalidades "estimular a criação cultural e o desenvolvimento do espírito científico e do pensamento reflexivo" (BRASIL, 2008, p. 45). Partindo desse pressuposto, a educação superior tem como um de seus propósitos formar cidadãos que possam construir um conhecimento cultural reflexivo e que possam assim contribuir para uma sociedade mais justa, com igualdade entre os cidadãos. No sexto parágrafo do mesmo artigo da LDB, consta que a educação superior tem ainda a finalidade de "estimular o conhecimento dos problemas do mundo presente, [...] prestar serviço especializado à comunidade e estabelecer uma relação de reciprocidade" (BRASIL, 2008, p. 45). Diante do exposto, compreendemos que não importa o curso escolhido pelo indivíduo e sim o processo formativo que ele recebeu, além disso, o importante é que a formação subsidie o futuro profissional para que atue na sociedade de forma a combater as desigualdades sociais, o preconceito e a discriminação.

Mais especificamente no que se refere à formação docente, o Art. $2^{\circ}$ da Resolução no 1 de 18 de fevereiro de 2002, do Conselho Nacional de Educação/Conselho Pleno (CNE/CP) afirma que "a organização curricular de cada instituição observará, [...] formas de orientação inerentes à formação para a atividade docente, entre as quais o preparo para: [...] o acolhimento e o trato da diversidade [...]" (CNE/ CP, 2002, p. 01). Complementando essa ideia, foi publicada em 30 de maio de 2012, pelo Conselho Nacional de Educação (CNE), Conselho Pleno (CP), a Resolução no 1 . No Artigo $3^{\circ}$, parágrafos 1 e 2 , respectivamente, a resolução afirma que a Educação em Direitos Humanos, com a finalidade de promover a educação para a mudança e a transformação social, deverá se fundamentar, dentre outros, nos princípios da igualdade de direitos e no reconhecimento e valorização das diferenças e das diversidades. Já em seu Artigo 6 ${ }^{\circ}$, o documento determina que a Educação em Direitos Humanos, de modo transversal, deverá se fazer presente nos cursos de ensino superior; para tanto, ela deve ser considerada durante o processo de construção dos Projetos Político-Pedagógicos (PPP), dos Regimentos Escolares, dos Planos de Desenvolvimento Institucionais (PDI) e dos Programas Pedagógicos de Curso (PPC) das Instituições de Educação Superior, devendo também se fazer presente no modelo de ensino, na pesquisa e na extensão, dentre outros.

Em relação à formação docente, a referida Resolução estabelece que a educação em Direitos Humanos deverá orientar a formação inicial e continuada de todos os profissionais da educação. Nesse caso, determina, em seu Artigo $8^{\circ}$, a obrigatoriedade da inserção da Educação em Direitos Humanos como um componente curricular dos cursos de formação inicial e continuada de todos os profissionais da educação.

As determinações legais vêm subsidiar a formação docente, propiciando a compreensão de que ele, enquanto profissional, deve entender os problemas que permeiam a escola e o seu cotidiano, contribuindo com a construção de uma sociedade mais justa, sem preconceitos e discriminação, incluindo o de gênero.

De acordo com Louro (2007), os professores também se tornam responsáveis pela conduta de seus alunos, pois "não há dúvidas de que as atitudes respeitosas devem partir do professor, pois serão vistas como modelos, sobretudo pelas crianças menores" (BRASIL, 2000, p. 123), portanto o professor tem papel importante na formação, podendo contribuir com o desenvolvimento de comportamentos e virtudes que se manifestam além do ambiente escolar. Assim, cabe ao professor exemplificar ideias e atitudes que inspirem seus alunos a serem cidadãos críticos, reflexivos e que respeitam e valorizam a diversidade.

\section{A DISCIPLINA DE GEOGRAFIA COMO ME- DIADORA NA FORMAÇÃO CIDADÃ}

Para Silva (2013), a Geografia permite uma explicação do mundo, mas esta se torna mais completa quando se leva em consideração que o espaço geográfico é constituído de seres humanos que têm sexo e gênero, portanto, é fundamental que este dado biológico e cultural que marca as pessoas socialmente, economicamente e culturalmente seja levado em conta no momento da investigação geográfica.

Na escola, a Geografia, assim como as demais ciências sociais, tem o compromisso de contribuir para a formação integral do ser humano. Desse modo, a Geografia, como disciplina escolar, tem como meta contribuir para a formação do cidadão e da cidadã que participam dos movimentos promovidos pela sociedade e que conhecem o seu papel no interior das várias instituições das quais participam. Apesar da existência desse compromisso, sabemos que na maioria das vezes se torna muito difícil a efetivação na prática dessa incumbência no espaço social denominado escola (COSTA, 2011).

Vale ressaltar que o

[...] espaço geográfico brasileiro é analisado e interpretado pela Geografia, estando repleto de conflitos, de vários grupos sociais que lutam por igualdade e reconhecimento. Nessa perspectiva, é importante propor um diálogo nas aulas de Geografia sobre gênero e diversidade, demonstrando aos alunos que é preciso avançar em busca de uma sociedade mais justa, diante de tanta desigualdade que permeia o espaço geográfico brasileiro (SILVA; VALE, 2015, p. 1). 
Assim, a introdução da categoria gênero no ensino de Geografia na Educação Básica é uma das formas de os professores que lecionam essa disciplina promoverem uma educação cidadã, contribuindo para a construção de uma sociedade que respeita as diferenças, pois a abordagem geográfica dessa categoria

[...] representa quebra de paradigmas e enfrentamento de preconceitos [...], trabalhar com conceitos feministas nas ciências humanas e sociais é, ao mesmo tempo, assumir um comprometimento político com a transformação do mundo, e assumir uma postura teórico-metodológica empenhada com o desvendamento de categorias e conceitos supostamente neutros [...] (SILVA, 2013, p. 107).

Portanto, uma Geografia que, de forma explícita, considera a estrutura de gênero da sociedade assume o compromisso de, através da transformação/mudança social, atenuar em curto prazo as desigualdades baseadas no gênero e em longo prazo eliminá-las. (WGSG, 1984 apud SILVA, 2013, p. 108).

Segundo Silva (2009, p. 41), “[...] mesmo frente à crescente importância do papel feminino nos fatos sociais, a Geografia brasileira permanece negligenciando a perspectiva de gênero como potencialidade de construção da inteligibilidade da realidade socioespacial" e essa negligência da ciência geográfica reflete na formação do professor de Geografia e do trabalho com o tema gênero na escola e na sala de aula. Para Silva (2003), citada por Costa (2011), há, na atualidade, a necessidade de um envolvimento coletivo dos professores nas discussões e estratégias que abordam a melhoria do ensino de Geografia, bem como da criação de um compromisso com o ensino democrático e com uma escola cidadã. Para ajudar nesse processo, os Parâmetros Curriculares Nacionais (PCNs) foram lançados com o intuito de oferecer à comunidade escolar e aos professores em particular uma referência nacional do que deve ser trabalhado em sala de aula e de como fazê-lo. Eles apontam os elementos essenciais do que se pretende para a Educação Básica brasileira. Entre as ações propostas pelos PCNs, está o trabalho com temas transversais. Os temas transversais abordam questões sociais cotidianas e urgentes que precisam ser tratadas em sala de aula e por toda a comunidade escolar, sendo os temas eleitos para serem desenvolvidos no Ensino Fundamental e Médio a ética, a pluralidade cultural, o meio ambiente, a saúde, a orientação sexual e o trabalho e consumo. Esses assuntos não precisam de disciplinas específicas, pois devem ser trabalhados em todos os componentes curriculares, por serem pontos que atravessam diversas áreas do conhecimento, sendo, segundo Costa (2011, p. 79), a "integração dos diferentes campos do saber importante para que o estudante conheça seu papel na sociedade e no mundo em que vive". Para a efetivação de uma ação docente interdisciplinar é fundamental que o pro- fessor ou professora detenha um conhecimento aprofundado sobre a ciência da qual é especialista e estabeleça a interface com as demais disciplinas, no sentido de complementar o conhecimento de determinados temas e objeto de pesquisa.

$\mathrm{O}$ trabalho com os temas transversais não obriga

[...] os professores das diferentes áreas [a] [...] "parar" sua programação [...], mas sim de que explicitem as relações entre ambos e as incluam como conteúdos de sua área, articulando a finalidade do estudo escolar com as questões sociais, possibilitando aos alunos o uso dos conhecimentos escolares em sua vida extra escolar. Não se trata, portanto, de trabalhá-los paralelamente, mas de trazer para os conteúdos e para a metodologia da área a perspectiva dos temas (BRASIL, 1998, p. 27).

Nessa perspectiva, a educação deve não apenas transmitir conhecimentos científicos e preparar um indivíduo para exercer uma profissão, mas também, entre outros aspectos, preparar o aluno para conhecer a diversidade da espécie humana, possibilitando que ele tome consciência das semelhanças e da interdependência entre todos os seres humanos, pois a escola tem a responsabilidade de utilizar todas as ocasiões para promover esse aprendizado, sabendo que algumas disciplinas estão mais aptas para esse fim, em particular a Geografia (DELORS, 2003 apud VELOSO; ALMEIDA 2013).

O ensino da Geografia Escolar, com sua diversidade de temas, permite constantemente momentos de interlocução entre os assuntos específicos estudados na disciplina e os temas transversais. Além disso, algumas temáticas são tratadas com especificidade na ciência geográfica. Esse é o caso da Geografia de Gênero que "busca promover, através de estudos nas últimas décadas, a ruptura dos padrões espaciais impostos por uma sociedade patriarcal. Contudo, dessa nova área da ciência geográfica, pouco conhecida é sua abordagem na escola" (ALMEIDA; MARTINS 2011, p. 12935). Ressalta-se que não é apenas papel da Geografia o trabalho com os temas transversais, mas também de todas as disciplinas que compõem a Educação Básica. Cabe à Geografia, devido à facilidade com que "a disciplina relaciona com tranquilidade os temas com afinidades tanto com cidadania quanto com a igualdade de gênero" (ALMEIDA; MARTINS, 2011, p. 12937), engendrar esforços para que a formação escolar cumpra seu papel de despertar nos alunos a consciência cidadã, combatendo as manifestações preconceituosas e discriminatórias. Portanto, o professor deve voltar seu trabalho à formação de cidadãos crítico-reflexivos, que possam compreender, analisar, refletir sobre os problemas que circundam o meio em que eles estão inseridos, construindo valores que tenham por objetivo promover o respeito às diferenças e à diversidade, combatendo o preconceito nas suas mais variadas formas. Assim sendo,

As contribuições da Geografia escolar à formação de uma 
consciência espacial-cidadã estão relacionadas ao significado político cultural do trabalho pedagógico, por isto o papel do professor que deve estar compromissado com a intervenção em sua realidade sócio-espacial, desde suas dimensões locais às mais globais (BRAGA, 2012, p. 3).

Alguns temas como as questões ligadas ao preconceito de gênero estão particularmente presentes na sala de aula de Geografia, podendo ser trabalhadas no sentido de minimizar a discriminação existente entre homens e mulheres. Esse tema pode ser analisado a partir da inserção da mulher no mercado de trabalho; do papel da mulher na família; da distribuição espacial dos contingentes femininos; da exclusão das mulheres nas decisões políticas;

[...] [da] feminização da pobreza, [...] [do] aumento da proporção de mulheres chefes de família, [...] [das] migrações femininas no mundo, [...] [das] economias nacionais baseadas em remessas de capitais e como esses elementos redesenham as relações entre os sexos nos locais de origem, [...] [da] participação das mulheres nos movimentos camponeses (como no Movimento dos Sem-Terra), e, acima de tudo, [...] [dos] desiguais efeitos que, sobre as mulheres e homens, estão produzindo a globalização [...] (SILVA et al., 2009, p. 40).

Espera-se que, no trabalho com essas e outras questões, a postura do professor denote a rejeição a qualquer tipo de discriminação, focando suas abordagens na igualdade de gênero e nas razões históricas dessa desigualdade, pois ensinar, segundo Freire (2011), exige rejeição a qualquer forma de discriminação. Portanto, cabe ao professor tomar atitudes não preconceituosas, democráticas pluralistas e estar preparado para trabalhar com questões sociais que muitas vezes são ocorrências inesperadas no cotidiano e saber o momento correto de incluir nas aulas os conteúdos, de forma direta ou indireta, desde que seja de maneira coerente sobre a valorização da equidade entre homens e mulheres, a valorização da dignidade dos indivíduos, explicando como ocorrem os preconceitos de gênero e os estereótipos.

Tomando essa atitude, o professor estará contribuindo com a não discriminação de gênero, construindo junto com os alunos uma sociedade mais igualitária e colocando em prática os objetivos dos PCNs em que os alunos devem ser capazes de "identificar e repensar tabus e preconceitos, [...] evitando comportamentos discriminatórios e intolerantes e analisando criticamente os estereótipos" (BRASIL, 1998 p. 311).

Apesar das orientações contidas nos PCNs, existem, segundo Costa (2011), alguns elementos como a falta de formação docente adequada, a carência de debates sobre o tema, a ausência ou superficialidade da abordagem do tema nos livros didáticos de Geografia e os preconceitos, acabam por gerar um silêncio nos espaços escolares que dificulta $\mathrm{O}$ trato com as questões de gênero, tendo essa ação o objetivo de manter a ordem vigente. Outro ponto que dificulta é, segundo Junckes e Silva (2009), que essas instituições ainda são no Brasil espaços de vivência da discriminação, preconceito e exclusão de pessoas que não seguem as normas impostas pela heteronormatividade.

Assim, para obter êxito no combate ao preconceito, a postura do professor deve ser corroborada por toda a comunidade escolar, ou seja, a direção, os professores e funcionários devem demonstrar para os alunos o respeito mútuo, o apreço pela ética e pelos princípios de cidadania, criando um ambiente que ensine pelo exemplo, que não se omita diante de temas considerados delicados e que se mostre aberto à discussão e à reconstrução constante de seu fazer pedagógico.

\section{A PESQUISA NA ESCOLA CAMPO DO ES- TÁGIO}

Diante da situação da mulher no Brasil e no estado de Alagoas, que apresenta uma taxa de homicídios de mulheres de 8.3 para cada grupo de 100 mil mulheres, índice bem acima da média nacional que é de 4.4 e que tem a sua capital, Maceió, na $14^{\mathrm{a}}$ posição em assassinatos de mulheres entre as capitais do país e o município de Arapiraca, segunda maior cidade do estado, na $4^{\text {a }}$ posição entre os municípios brasileiros (WAISELFISZ, 2012), tem-se a compreensão da importância de que os cursos que formam os futuros professores de Geografia devem fomentar pesquisas e debates que visem à luta pelos direitos das mulheres. Pois, se o professor não possui uma formação inicial que contemple a categoria gênero, dificilmente ele dedicará um espaço em sua aula para abordar questões ligadas a essa temática (COSTA, 2011), assim como a outros temas que ajudem na formação cidadã de seus alunos e na diminuição do preconceito. Nesse contexto, evidencia-se que a escola e os professores de Geografia, incluindo os das demais disciplinas, possuem papel fundamental para a promoção de modificações em relação à visão social sobre as questões ligadas ao preconceito e à violência contra a mulher.

Diante dessa realidade, realizou-se uma pesquisa na escola campo de estágio para buscar saber quais as percepções dos alunos sobre questões ligadas ao preconceito de gênero.

O elemento motivador da pesquisa foi um anúncio da revendedora da marca Dafra Motos exibido em outdoors da cidade de Maceió, capital do estado de Alagoas, no qual se evidenciava uma mulher em poses eróticas sobre uma moto com uma frase escrita com letras maiúsculas: "Compre que eu dou pra você" e, logo abaixo, os dizeres, em letras menores, "o emplacamento grátis", completando o sentido da primeira frase (Figura 1, 2 e 3).

A referida propaganda gerou polêmica na cidade, sendo ela considerada, pelo Programa de Proteção e Defesa 
do Consumidor de Alagoas (PROCON-AL), como abusiva. Segundo o Código de Defesa do Consumidor, Art. 37 parágrafo $2^{\circ}$,

é abusiva [...] a publicidade discriminatória de qualquer natureza, a que incite à violência, explore o medo ou a superstição, se aproveite da deficiência de julgamento e experiência da criança, desrespeita valores ambientais, ou que seja capaz de induzir o consumidor a se comportar de forma prejudicial ou perigosa à sua saúde ou segurança (BRASIL, 2001, p. 25, grifo nosso).

Ressalta-se que a propaganda foi retirada das ruas após várias denúncias feitas ao Ministério Público (MP) e ao PROCON, que consideraram o conteúdo apelativo, abusivo, depreciativo e nocivo, instigando a discriminação de gênero. Por expor e evidenciar a mulher como objeto sexual, o Conselho Nacional de Autorregulamentação Publicitária (CONAR) também determinou a suspensão dos anúncios nos meios de comunicação.
Esse anúncio foi o elemento base para a elaboração do questionário que deu início à pesquisa desenvolvida na disciplina de Estágio Supervisionado II do curso de Geografia Licenciatura da Universidade Federal de Alagoas (UFAL). O trabalho de investigação teve como objetivo trabalhar com os licenciandos aspectos ligados às questões de gênero e ao papel da escola juntamente com a Geografia na diminuição do preconceito e da violência contra a mulher.

A metodologia utilizada foi a qualitativa, pois essa exige daqueles que a adotam o "desenvolvimento de uma capacidade criadora e intuitiva" (MARTINS, 2004, p. 292). Utilizou-se, na apreciação dos dados, a análise de conteúdo a partir do paradigma interpretativo. $\mathrm{O}$ método da análise de conteúdo aparece como uma ferramenta para a compreensão da construção de significado que os atores sociais exteriorizam no discurso, permitindo ao pesquisador o entendimento das representações que o indivíduo apresenta em relação a sua realidade e a interpretação que faz dos significados a sua volta (SILVA; GOBBI; SIMÃO, 2005).

\section{Figura 1}

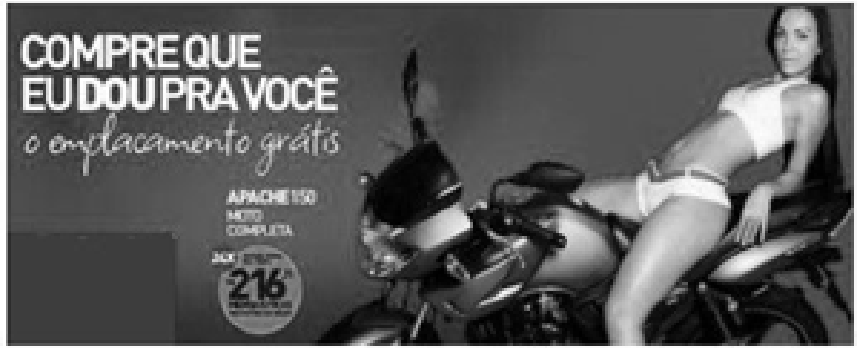

\section{Figura 2}

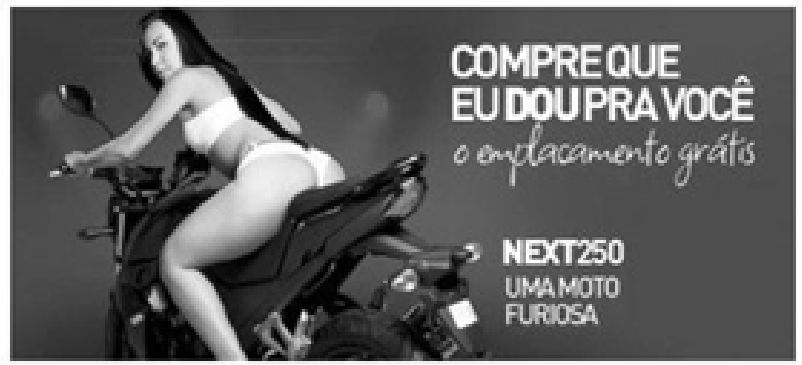

Fonte: http://www.geracaoduasrodas.com.br/propaganda-da-dafra-causa-polemica-em-maceio/

Ffiguras 1 e 2 - Anúncio da revendedora da marca Dafra Motos exibido em outdoors da cidade de Maceió

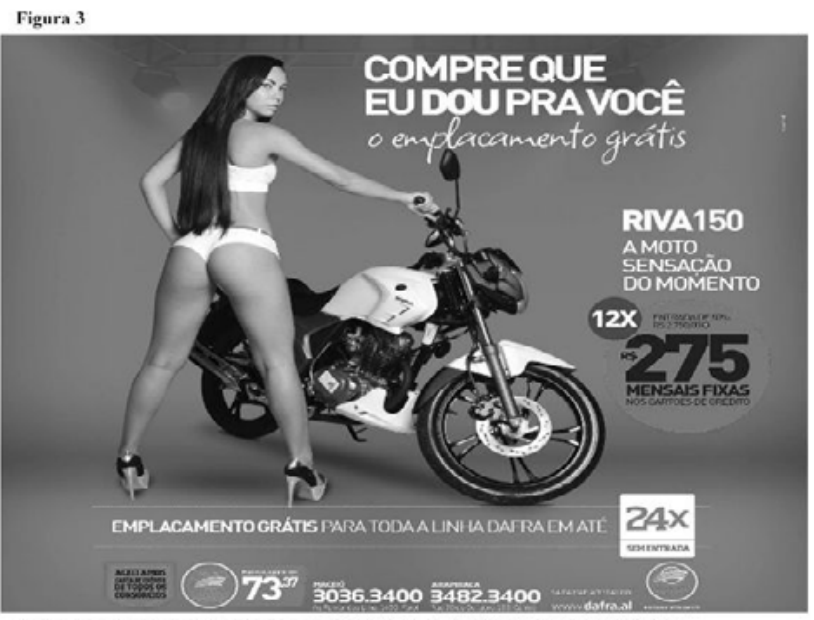

Fonte: http://www.bestriders.com.br/propaganda-da-dafra-causa-polemica-em-maceio

Figura 3- Anúncio da revendedora da marca Dafra Motos exibido em outdoors da cidade de Maceió
Desse modo, por ser especialmente aplicado na exploração, descoberta e interpretação, utilizou-se o paradigma interpretativo, buscando proporcionar um procedimento mais intuitivo, mais maleável e mais adaptável (BELL, 1997) desse trabalho de investigação, permitindo, dessa forma, compreender como os inquiridos interpretam o ambiente onde atuam e como influenciam o ambiente (ALENCAR, 2002 apud SILVA; GOBBI; SIMÃO, 2005).

A pesquisa foi realizada em uma escola pública de Maceió, cujo universo era de 1.324 alunos do Ensino Médio. Foram inquiridos 456 estudantes, o que correspondeu a 35\% do total. A maioria dos pesquisados, $50 \%$, apresentava-se na faixa etária dos 14 aos 16 anos e $51 \%$ do total de pesquisados eram do sexo feminino.

O primeiro questionamento feito aos alunos foi se a propaganda da Dafra Motos era de fundo machista. A maioria dos alunos afirmou que $\operatorname{sim}(71 \%)$ e o restante $(29 \%)$ res- 
pondeu que não. Os $29 \%$ que afirmaram que o anúncio não era de fundo machista justificaram sua resposta afirmando que a propaganda era normal e que só era considerada machista por pessoas conservadoras. Na sociedade brasileira, "a associação entre o capitalismo e o patriarcado, que transfor$\mathrm{ma}$ as mulheres em objeto, está no centro da violência sexista" (ALAGOAS, 2012), ajudando a banalizar a desvalorização da mulher, estando essa concepção presente na resposta dos alunos.

Também foi perguntado aos discentes se a propagan$\mathrm{da}$, por ter sido considerada ousada, deveria continuar sendo exibida nas ruas. A maior parte dos inquiridos $(62 \%)$ afirmou que não e o restante $(38 \%)$ alegou que sim. Os que foram contra a retirada da propaganda das ruas se justificaram afirmando que era uma publicidade normal, que deveria ser mantida em respeito à liberdade de expressão e por incomodar apenas as pessoas conservadoras. Segundo Meyer (2008), nós aprendemos a ser homens e mulheres desde o momento em que nascemos até o dia em que morremos, tendo a mídia, dentre outras criações sociais, participação significativa nesse processo. As propagandas ajudam a moldar as representações de gênero em crianças e jovens, sendo a mídia artefato potente na construção da visão social de gênero, de sexualidade, dentre outras identidades culturais. Portanto, a mídia oferece linguagens, códigos e modelos de como se tornar um homem ou uma mulher que atenda a um modelo pré-estabelecido (SOARES, 2008). As práticas exercidas pela mídia são, em grande parte, consideradas naturais, não sendo postas, na maioria das vezes, em questão. Tal "naturalidade" fortemente construída tem impedido as pessoas, por exemplo, de verem a espetacularização dos corpos, as divisões de gênero e a sexualidade voltada, principalmente, para a figura feminina como objeto de desejo sexual (SOARES, 2008). Essa "naturalidade" na exposição do corpo feminino e a sua apresentação como objeto de desejo estão presentes nas respostas dos alunos, bem como a percepção de que, por ser algo "natural", só irá incomodar aqueles com visão mais estreita e arcaica.

Com o intuito de conhecer a percepção dos alunos sobre a questão geracional, foi introduzido no questionário o elemento ficcional de uma senhora acima dos 60 anos como sendo a primeira a fazer a reclamação ao PROCON-AL, sendo perguntado, por último aos alunos, se a atitude tomada pela idosa que denunciou a propaganda está relacionada à sua idade. A maioria dos alunos afirmou que não (54\%) e o restante $(46 \%)$ afirmou que sim, dando como justificativa que as pessoas mais velhas são mais antiquadas e têm inveja da beleza das pessoas mais novas. Nessa questão, deve-se levar em consideração que está presente no imaginário dos alunos não só a desvalorização da mulher, mas também a visão de que "a forma do corpo (suas características formais, tipo volume, vigor, beleza) é [...] um indicador de poder social e prestígio (MENEZES; LOPES; AZEVEDO, 2009, p. 602), como também estão embutidas a cobrança e a valorização social de um corpo feminino jovem, belo, sexuado e desejável (LIMA; BUENO, 2009), não sendo considerada a existência de uma beleza feminina fora desses padrões da efemeridade da juventude. Assim, percebe-se nas respostas dos alunos tanto o descaso com a questão da desvalorização feminina, como o preconceito geracional, pois a ação tomada pela senhora contra a exibição da propaganda não foi vista como algo relacionado aos valores sociais, mas sim à idade.

Destaca-se que o desenvolvimento desta pesquisa na escola campo de estágio foi fundamental para promover um conhecimento mais aprofundado dos alunos pelos licenciandos, além de promover, durante o processo de condução do Estágio, debates e reflexões sobre a situação da mulher em Alagoas, sobre o papel da escola e do professor de Geografia diante da realidade que se apresenta no estado e no espaço escolar sobre as questões de gênero.

\section{CONSIDERAÇÕES FINAIS}

O problema do preconceito, da desvalorização e da violência contra a mulher é um problema estrutural da sociedade brasileira e, em especial, da alagoana. Diante disso, fica claro que a escola e o professor possuem uma parcela de responsabilidade em impulsionar mudança nessa realidade, contribuindo para a construção de uma nova postura ético-valorativa de recolocar valores humanos fundamentais como a justiça, a solidariedade, a honestidade, o reconhecimento da diversidade e da diferença, o respeito à vida e aos direitos humanos básicos, como suportes de convicções democráticas (LIBÂNEO, 2003, p. 8).

Nesse contexto, a disciplina Geografia, por ter entre seus objetivos o de trabalhar com questões do cotidiano, pode ser um agente a contribuir com tais mudanças, propondo, em sua abordagem, temas que permitam discutir, à luz da realidade brasileira, assuntos relacionados às ações humanas que podem expressar preconceitos e discriminações, bem como evidenciar, em seus conteúdos, assuntos relacionados à ética, ajudando, ao estudar as questões sociais, a desenvolver nos alunos atitudes éticas diante das diversas situações que permeiam a sociedade brasileira. Assim, cabe ao professor de Geografia preocupar-se com a educação cidadã de seus alunos, mostrando-lhes a capacidade que possuem de serem e de se reconhecerem como atores e construtores da realidade em que estão inseridos.

Apesar de os resultados obtidos terem mostrado que a maioria dos alunos entenderam que a propaganda tinha uma conotação machista, que era ofensiva e feria princípios 
éticos e legais e, por isso, deveria ser retirada das ruas e embora tenham percebido que a denúncia feita pela senhora estava ligada às questões relacionadas à desvalorização da mulher, à utilização de sua imagem como objeto sexual e aos valores humanos ligados ao respeito ao outro, tivemos percentuais significativos de entrevistados que banalizaram e naturalizaram a conotação machista da propaganda, a desvalorização da mulher e a utilização de sua imagem como objeto de desejo.

Em um país e em um estado que apresentam índices preocupantes de preconceito e violência contra a mulher, os resultados da pesquisa ajudaram os licenciandos, envolvidos na investigação, a refletirem sobre a importância da escola e do trabalho do professor como agentes corresponsáveis pela formação cidadã de seus alunos e pela construção de sujeitos que repudiam desigualdades, discriminações e preconceitos.

\section{REFERÊNCIAS}

ALAGOAS. Relatório do Movimento de Mulheres sobre a Violência contra as Mulheres em Alagoas. Maceió: [s.n.], 2012.

ALMEIDA, A. C. C.; MARTINS, E. B. Relacionando cidadania feminina e Geografia: como mediar no ensino fundamental?. In: CONGRESSO NACIONAL DE EDUCAÇÃO (EDUCERE) / I SEMINÁRIO INTERNACIONAL DE REPRESENTAÇÕES SOCIAIS, SUBJETIVIDADES E EDUCAÇÃO (SIRSSE), 10., Curitiba. Anais... Curitiba: PUCPR, 2011. p. 12933- 12942. Disponível em: <http://educere.bruc.com.br/CD2011/ pdf/5554_3716.pdf>. Acesso em: 21 jan. 2015.

ALMEIDA, J. P. O curso de pedagogia da Universidade Federal de Alagoas e a formação docente para a prática da educação inclusiva. 2014. 268f. Tese (Doutorado em Ciências da Educação) - Universidade de Évora, Évora, 2014.

ARBEX, D. Holocausto Brasileiro. São Paulo: Geração Editorial, 2010.

BELL, J. Como realizar um projeto de investigação. Lisboa: Gradiva, 1997.

BRAGA, F. S. A Prática da Consciência Cidadã nos Cursos de Formação de Professores de Geografia no Brasil e em Portugal: Primeiras Análises. In: INTERNATIONAL COLLOQUIUM CITIZENSHIP AND KNOWLED-
GE SOCIETY, Actas... Lisboa, dezembro 2012.

BRASIL. Parâmetros Curriculares Nacionais: terceiro e quarto ciclos: apresentação dos temas transversais / Secretaria de Educação Fundamental. Brasília: MEC/SEF, 1998. $436 \mathrm{p}$.

BRASIL. Parâmetros curriculares nacionais: apresentação dos temas transversais: ética. ed. 2. Rio de Janeiro: Secretaria de Educação Fundamental, 2000.

BRASIL. Código de Defesa do Consumidor. Nova ed. rev., atual. e ampl. com o Decreto $n^{\circ} 2.181$, de 20 de março de 1.997. Brasilia: Ministério da Justiça, 2001.

BRASIL. LDB: Lei de Diretrizes e Bases da Educação Nacional. Rio de Janeiro: Lamparina, 2008.

BRASIL. Gênero e diversidade na escola: formação de professoras/es em Gênero, Orientação Sexual e Relações Étnico-Raciais. Livro de conteúdo. Rio de Janeiro: CEPESC, 2009.

BUTLER, J. Problemas de gênero: feminismo e subversão da identidade. Rio de Janeiro: Civilização Brasileira, 2003.

CASAGRANDE, L. S.; CARVALHO, M. G. de; SILVA, N. $S$. Construindo a igualdade na escola: repensando conceitos e preconceitos de gênero. In: CONGRESSO NACIONAL DE EDUCAÇÃO (EDUCERE)/ III ENCONTRO SUL BRASILEIRO DE PSICOPEDAGOGIA, 9., 2009, Curitiba. Anais... Curitiba: PUCPR, 2009. p. 2554-2565. Disponível em: <http://www.pucpr.br/eventos/educere/ educere2009/anais/pdf/2468_1309.pdf>. Acesso em: 21 jan. 2015.

CONSELHO NACIONAL DE EDUCAÇÃO/CONSELHO PLENO [CNE/CP]. Resolução CNE/CP 1, de 18 de fevereiro de 2002. Institui Diretrizes Curriculares Nacionais para a Formação de Professores da Educação Básica, em nível superior, curso de licenciatura, de graduação plena, 2002.

COSTA, C. L. A presença e ausência do debate de gênero na Geografia do Ensino Fundamental e Médio. Revista Latino-americana de Geografia e Gênero, Ponta Grossa, v. 2, n. 2, p. 76-84, ago./dez., 2011.

FREIRE, P. Pedagogia da autonomia: saberes neces- 
sários à prática educativa. São Paulo: Paz e Terra, 2011.

IPEA. Violência contra a mulher: feminicídios no Brasil. Brasilia: IPEA, 2013.

IPEA.O Sistema de Indicadores de Percepção Social (SIPS). Tolerância social à violência contra as mulheres. Brasilia: IPEA, 2014.

JUNCKES, I. J.; SILVA, J. M. Espaço escolar e diversidade sexual: um desafio às políticas educacionais no Brasil. Revista de Didácticas Específicas, Madri, n. 1, p. 148-166, dez., 2009.

LIBÂNEO, J. C. et al. Educação escolar: políticas, estrutura e organização. São Paulo: Cortez, 2003.

LIMA, L. C. V. de; BUENO, C. M. L. B. Envelhecimento e gênero: a vulnerabilidade de idosas no Brasil. Revista Saúde e Pesquisa, Maringá, v. 2, n. 2, p. 273-280, mai./ ago., 2009.

LOURO, G. L. Gênero, sexualidade e educação: uma perspectiva pós-estruturalista. $9^{\circ}$ ed. Petrópolis: Vozes, 2007.

MARQUES, M. R. A. Imagens Femininas e Masculinas no Livro Didático: subsídios para um debate teórico-metodológico. In: MELO, H. P. de. et al. (Orgs). Olhares Feministas. Brasilia: MEC/UNESCO, 2006, p. 209-221.

MARTINS, H. H. T. de S. Metodologia qualitativa de pesquisa. Revista Educação e Pesquisa, São Paulo, vol. 30, n. 2, p. 289-300, maio/ago. 2004.

MENEZES, T. M. de O.; LOPES, R. L. M.; AZEVEDO, R. F. A pessoa idosa e o corpo: uma transformação inevitável. Revista Eletrônica de Enfermagem: Revista da Faculdade de Enfermagem da Universidade Federal de Goiás, Goiânia, v. 11, n. 3, p. 598-604, 2009.

MEYER, D. E. Gênero, sexualidade e currículo. In: BRASIL. Salto para o Futuro. Educação para a igualdade de gênero. Brasilia: MEC, 2008.

PINSKY, J. (Org.). 12 faces do preconceito. 11. ed. São Paulo: contexto, 2014.

SILVA, C. R.; GOBBI, B. C.; SIMÃO, A. A. O uso da análise de conteúdo como uma ferramenta para a Pesquisa qua- litativa: descrição e aplicação do método. Revista Organizações Rurais Agroindústria, Lavras, v. 7, n. 1, p. 70-81, 2005.

SILVA, J. M. et al. Geografia e gênero no Brasil: uma análise da feminização do campo científico. Revista Ateliê Geográfico, Goiânia. v. 3, n. 2, p.38-62, set., 2009.

SILVA, S. G. da. Preconceito e discriminação: as bases da violência contra a mulher. Psicol. cienc. prof. [online]. v. 30, n.3, p. 556-571, 2010.

SILVA, S. L. da; VALE, S. A. Os temas transversais gênero e diversidade nas aulas de geografia. In: ENCONTRO NACIONAL DE ENSINO DE GEOGRAFIA, 7., 2015, Catalão. Anais... Catalão: UFG, 2015. p. 1-5. Disponível em: $<$ http://www.falaprofessor2015.agb.org.br/resources/ anais/5/1441036028_ARQUIVO_OSTEMASTRANSVERSAISGENEROEDIVERSIDADENASAULASDEGEOGRAFIA-FALAPROFESSOR.pdf>. Acesso em: 15 set. 2016.

SILVA, S. M. V. da. Contribuição dos estudos de gênero para a compreensão da geografia do trabalho: uma pauta para discussão. Revista Latino-americana de Geografia e Gênero, Ponta Grossa, v. 4, n. 2, p.106-117, ago./dez., 2013.

SOARES, R. Pedagogias culturais produzindo identidades. In: BRASIL. Salto para o Futuro. Educação para a igualdade de gênero. Brasilia: MEC, 2008.

SOUZA, L. F. de; RATTS, A. J. P. Raça e gênero sob uma perspectiva geográfica: espaço e representação. Boletim Goiano de Geografia, Goiânia, v. 28 n. 1 p. 143-156, jan./ jun., 2008.

VELOSO, D. A.; ALMEIDA, J. P. de. Currículo e a formação do professor de Geografia para o trabalho com a diversidade: homossexualidade na escola. In: COLÓQUIO INTERNACIONAL DE POLÍTICAS E PRÁTICAS CURRICULARES, 6., 2013, João Pessoa. Anais... João Pessoa: UFPB, 2013. p. 1891- 1896. Disponível em: $<$ http://geppc.org.br/sites/default/files/uploads/evento/203/anais/gt13-curriculoegeneroesexualidade.pdf $>$. Acesso em: 03 fev. 2015.

WAISELFISZ, J. J. Mapa da violência 2012 caderno complementar 1: homicídio de mulheres no Brasil. São 
Paulo: Instituto Sangari, 2012.

\section{Correspondência dos autores:}

Jacqueline Praxedes Almeida

e-mail: jacquepdealmeida@yahoo.com.br

Denis Rocha Calazans

e-mail: denisrc1@yahoo.com.br

Jaqueline Silva Bomfim

e-mail: jaquelinedasilvabomfim@gmail.com

Jeremias Ferreira Oliveira

e-mail: jeremiasferreiraufal@hotmail.com

Artigo recebido em: 21/10/2016

Revisado pelo autor em: 01/04/2017

Aceito para publicação em: 04/05/2017 